\title{
Molecular Bilateral Symmetry of Natural Products: Prediction of Selectivity of Dimeric Molecules by Density Functional Theory and Semiempirical Calculations
}

Tatyana Voloshchuk, Nicola S. Farina, Orrette R. Wauchope, Magdalena Kiprowska, Paul Haberfield, and Alexander Greer*

Department of Chemistry, Graduate School and University Center and The City

University of New York (CUNY), Brooklyn College, Brooklyn, New York 11210

*Author to whom correspondence should be addressed. Tel: 718-951-5475.

Fax: 718-951-4607. Email: agreer@brooklyn.cuny.edu

\section{Supporting Information}

\section{Table of Contents}

Page

S1 Table of Contents

S2-3 Computational details of dimers, trimers, and tetramers

S4-7 Table S1 
The carbon numbering scheme in which the bond distances and bond energies are described is shown in Table S1. AM1, B3LYP/D95**//AM1, HF/3-21G//AM1, and ONIOM calculations predict that $\mathrm{C}-\mathrm{C}$ bond strengths span a range from 45.0 to $110.3 \mathrm{kcal} / \mathrm{mol}$ in the dimeric structures.

Compound 1 possesses a C-1-C-2 bond of $110.3 \mathrm{kcal} / \mathrm{mol}$ in energy predicted from the AM1 computed homolysis in a unimolecular cleavage reaction. The $\mathrm{C}-1-\mathrm{C}-2$ biaryl bond strength is greater in the dimer is compared to the $\mathrm{C}-1-\mathrm{C}-2$ bond of the trimer $\mathbf{1 B}$ (101.8 $\mathrm{kcal} / \mathrm{mol})$ and tetramer $1 \mathrm{C}(97.0 \mathrm{kcal} / \mathrm{mol})$. From calculations at the HF/3-21G//AM1 level, the $\mathrm{C}-1-\mathrm{C}-2$ bond energy of $\mathbf{1}$ is enhanced compared to $\mathbf{1 B}$ by $16.2 \mathrm{kcal} / \mathrm{mol}$. The $\mathrm{C}-1-\mathrm{C}-2$ bond distances in $\mathbf{1}(1.463 \AA), \mathbf{1 B}(1.470 \AA)$, and $\mathbf{1 C}(1.473 \AA)$ increase incrementally further suggesting a progression for the facile homolysis of $\mathrm{C}-1-\mathrm{C}-2$ in the order $\mathbf{1 C}>\mathbf{1 B}>\mathbf{1}$. It should be noted that a different type of $\mathrm{C}-\mathrm{C}$ bond is formed in the progression from $\mathbf{1}$ to $\mathbf{1 B}$.

The natural product 2 was optimized with the AM1 and the ONIOM(B3LYP/D95**:AM1) methods as were the structures $\mathbf{2 B}$ and $\mathbf{2 C}$, which possessed added monomer units to yield hypothetical trimer and tetramer molecules. Subjective decisions were made to extend the cyclobutane substance so that it may be regarded as a trimer $(\mathbf{2 B})$ and a tetramer (2C). Envisioning other combinations to give a trimer and a tetramer would be just as valid. The AM1 method predicts an increase in the C-1-C-2 bond distance of $2(1.551 \AA)$ compared to $2 \mathbf{B}(1.557 \AA)$ and $2 \mathrm{C}(1.591 \AA)$, which suggests that the bonding arrangement in this series will lead to a more facile ionization with relief of steric crowding and ring strain. The C-1-C-2 distance is longer in 2 B $(0.007 \AA)$ and $2 \mathrm{C}(0.040 \AA)$ compared to the cyclobutane precursor, 2, which accompanies a weakening of the C1-C2 bonds that connect the subunits. The magnitude of the $\mathrm{C}-1-\mathrm{C}-2$ energy is reduced by $13.3 \mathrm{kcal} / \mathrm{mol}$ when comparing $\mathbf{2}$ to $\mathbf{2} \mathbf{B}$ and $54.6 \mathrm{kcal} / \mathrm{mol}$ when comparing $\mathbf{2 B}$ to $2 \mathrm{C}$. For this series, AM1 calculations of the $\mathrm{C}-1-\mathrm{C}-2$ bond energy are the result of an optimization with C-1 and C-2 separated at a fixed distance of 
3.0 A. The 2-layered ONIOM approach allowed an estimate of steric contributions. A similar situation is found where an $45.1 \mathrm{kcal} / \mathrm{mol}$ preference for $\mathrm{C}-1-\mathrm{C}-2$ in 2 relative to $\mathbf{2 C}$ that can be attributed to an enhanced steric demand and ring strain in $\mathbf{2 C}$.

We have also investigated the C-1—C-2 bond distance for bromophenol 11 (1.496 $⿱$ ), 11B (1.512 $\AA$ ), and 11C (1.516 $\AA$ ) with the AM1 method. Compound 11B possesses an additional aryl attachment at C-1. Compound 11C possesses aryl attachments at C-1 and C-3. Similarly, the evolution of energy upon rupture of the $\mathrm{C}-1-\mathrm{C}-2$ bond in the natural product dimer is more energetically costly compared to the hypothetical trimer or tetramer molecules. We calculated a 26.2 and $23.7 \mathrm{kcal} / \mathrm{mol}$ decrease in the $\mathrm{C}-1-\mathrm{C}-2$ bond strength in $\mathbf{1 1 B}$ and $\mathbf{1 1 C}$, respectively, when compared with 11. This is anticipated for branched ligands in $\mathbf{1 1 B}$ and $\mathbf{1 1 C}$, which can interact within the molecule via unfavorable steric interactions. Calculation at the B3LYP/6-31G*//AM1 level appears to corroborate the structural and energetic features predicted at the semiempirical AM1 level for the $\mathrm{C}-1-\mathrm{C}-2$ interaction energy between monomeric units in dimer 11, trimer 11B, and tetramer 11C.

The optimized structure of curcumin 12 possesses a stronger $\mathrm{C}-1-\mathrm{C}-2$ bond $(89.0$ $\mathrm{kcal} / \mathrm{mol})$ compared to $12 \mathrm{~B}(83.9 \mathrm{kcal} / \mathrm{mol})$ and $12 \mathrm{C}(66.6 \mathrm{kcal} / \mathrm{mol})$ according to unrestricted B3LYP/D95**//AM1 calculations. The C-1-C-2 distance is also longer in 12B (1.521 $\AA$ ) and 12C (1.536 $\AA$ ) compared to the curcumin precursor, 12 (1.507 $\AA$ ). Steric congestion also leads to preferential coordination of monomers as dimers rather than trimers and tetramers in sesquiterpene 13. The $\mathrm{C}-1-\mathrm{C}-2$ bond distance increases from $1.478(\mathbf{1 3})$ to $1.523 \AA(\mathbf{1 3 C})$ as revealed by AM1 calculations. The $\mathrm{C}-1-\mathrm{C}-2$ bond energy of the dimer is approximately $10-15$ $\mathrm{kcal} / \mathrm{mol}$ greater than that of the trimer and tetramer from AM1 calculations. The bond energy is similar for the calculated $\mathrm{C}-1-\mathrm{C}-2$ interaction at the HF/3-21G//AM1 level and is thought to reflect the relief of steric strain. 


compound

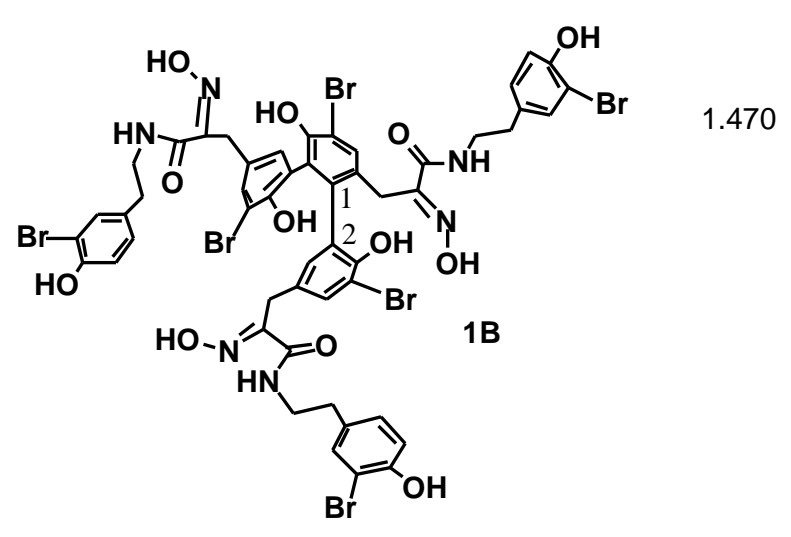

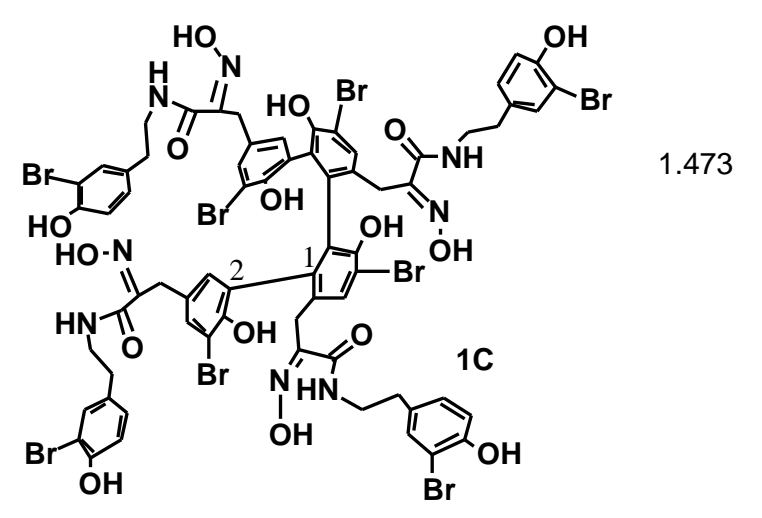

$97.0^{c}$ 

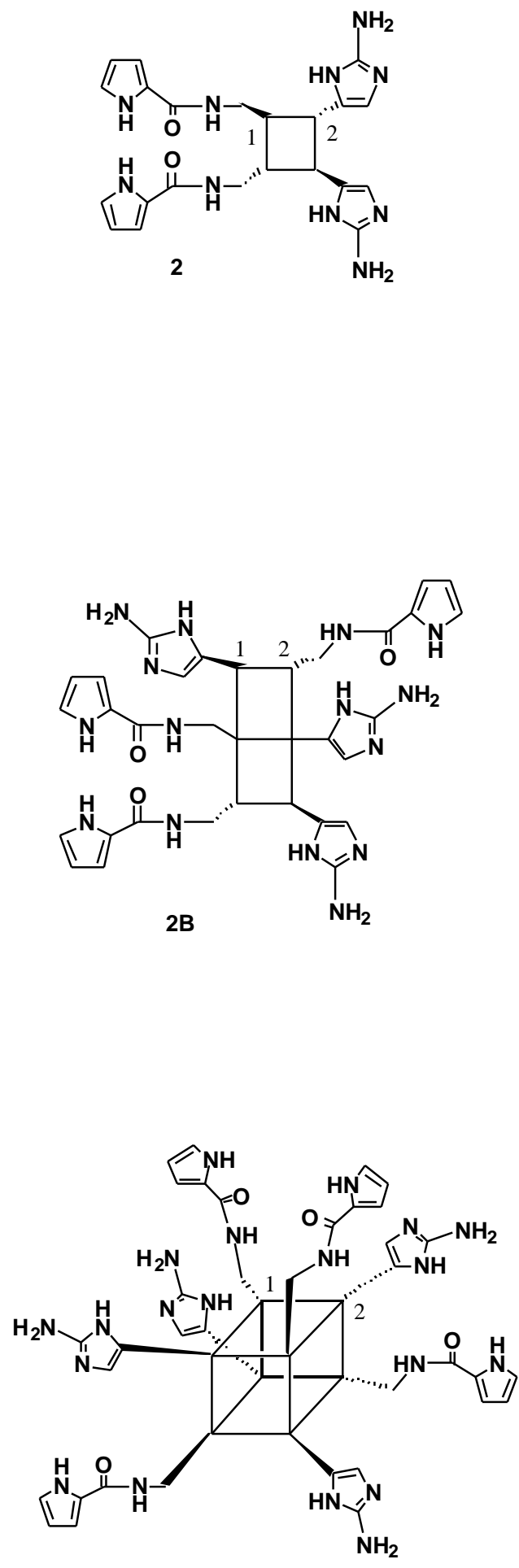

2C 
<smiles>Oc1cc(COCc2cc(O)c(O)c(Br)c2Br)c(Br)c(Br)c1O</smiles>

11

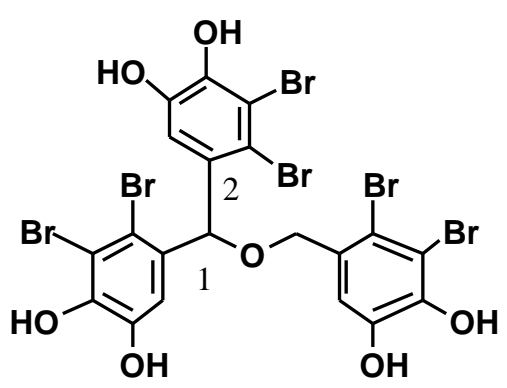

11B

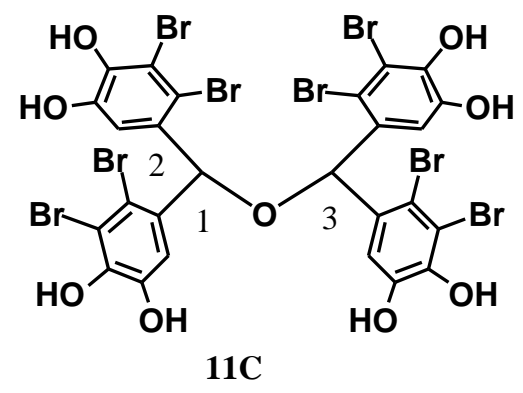

1.496

$74.0^{c}$

$103.6^{g}$

$49.9^{c}$

1.512

$77.4^{g}$ $50.5^{c}$

$79.9^{g}$ 


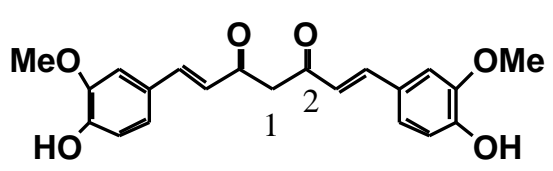

12

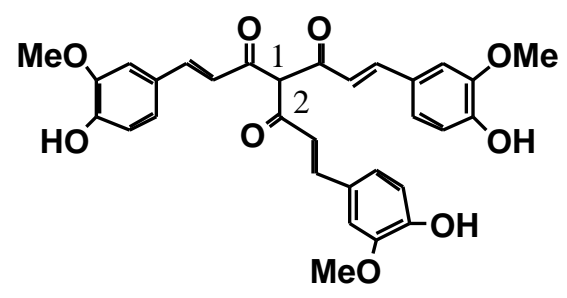

12B

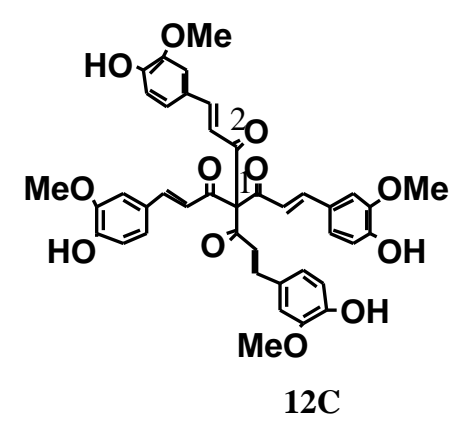


<smiles>Cc1ccc(C(C)C)cc2ccc(CI)c1-2</smiles>

13

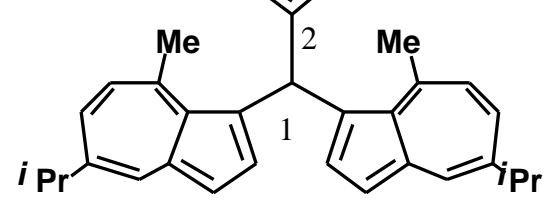

13B

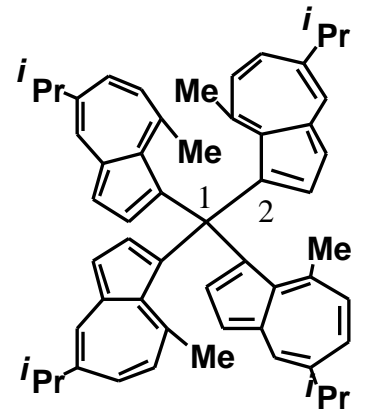

13C

${ }^{a}$ Distances in $\AA$; bond energies in $\mathrm{kcal} / \mathrm{mol} .{ }^{b}$ Trimers $(\mathbf{1 B}, \mathbf{3 B}, \mathbf{1 1 B}-\mathbf{1 3 B})$, tetramers $(\mathbf{1 C}, \mathbf{3 C}, \mathbf{1 1 C}-\mathbf{1 3 C})$, and oligomers with similar structures to 1, 2, and 11-13 appear to represent "missing" compounds in Nature. ${ }^{c}$ AM1 optimized geometries unless otherwise noted. Unrestricted AM1 calculations provided the $\mathrm{C}-\mathrm{C}$ bond homolysis energy. ${ }^{d} \mathrm{HF} / 3-21 \mathrm{G} / / \mathrm{AM} 1$ calculation. ${ }^{e}$ Restricted AM1 calculation with $\mathrm{C}-1-\mathrm{C}-2$ isolated at a fixed distance of 3.0 $\AA$. ${ }^{f}$ Restricted ONIOM(B3LYP/D95**:AM1) calculation optimized with the resulting species isolated at a fixed distance of $3.0 \AA$ A. ${ }^{\mathrm{g}} \mathrm{B} 3 \mathrm{LYP} / 6-31 \mathrm{G} * / / \mathrm{AM} 1$ calculation. ${ }^{h} \mathrm{~B} 3 \mathrm{LYP} / \mathrm{D} 95^{* *} / / \mathrm{AM} 1$ calculation. 